\title{
Essentials of Neonatal-Perinatal Medicine Fellowship: careers in Neonatal-Perinatal Medicine
}

\author{
Jennifer M. Trzaski (iD ${ }^{1 凶}$, Autumn S. Kiefer ${ }^{2}$, Patrick Myers $\mathbb{D}^{3}$, ONTPD Fellowship Directors Writing Group* and Lindsay C. Johnston ${ }^{4}$
}

(c) The Author(s), under exclusive licence to Springer Nature America, Inc. 2022

The clinical and academic landscape of Neonatal-Perinatal Medicine (NPM) is evolving. Career opportunities for neonatologists have been impacted by shifts in compensation and staffing needs in both academic and private settings. The workforce in NPM is changing with respect to age and gender. Recruiting candidates from backgrounds underrepresented in medicine is a priority. Developing flexible positions and ensuring equitable salaries is critically important. Professional niches including administration, education, research, and quality improvement provide many opportunities for scholarly pursuit. Challenges exist in recruiting, mentoring, funding, and retaining physician-scientists in NPM. Creative solutions are necessary to balance the needs of the NPM workforce with the growing numbers, locations, and complexity of patients. Addressing these challenges requires a multi-faceted approach including adapting educational curricula, supporting trainees in finding their niche, identifying novel ways to address work/life integration, and attracting candidates with both diverse backgrounds and academic interests.

Journal of Perinatology (2022) 42:1135-1140; https://doi.org/10.1038/s41372-022-01315-7

\section{INTRODUCTION}

Neonatal-Perinatal Medicine (NPM) has evolved with shifts in staffing, workforce composition, and promotional pathways. A historical perspective and current opportunities/threats are offered to prompt discussion amongst trainees charting career paths, program directors designing education, and NPM leaders guiding faculty recruitment, development, and retention to ensure NPM remains a rewarding career for future generations.

\section{EVOLUTION OF NPM PHYSICIAN PRACTICE}

Since the recognition of the field in the mid-1970s [1], the measure of a successful NPM career has been recalibrated in response to medical advances, patient safety metrics, changing compensation, and promotional criteria. The original academic ideal, a "triple threat" physician, excelling in research, teaching, and patient care, was limited by clinical supervision and documentation standards beginning in the 1980s [1,2]. During the 1990s, community NICUs offered careers with patient care as a greater focal point [3]. Despite reports of improved morbidity and mortality in infants born at level III+ facilities $[4,5]$ and efforts to regionalize perinatal care, NPM positions remain decentralized, particularly in states without limitations on hospital expansion [5]. Hybrid practice models, with providers cross-covering multiple NICUs, reduce distinctions between academic and private practice.

Neonatologists are meeting increased clinical needs across practice models. Attending in-house call has become more prevalent [6] and is associated with improved resuscitation outcomes and decreased NICU admissions [7, 8]. A recent fellowship program survey noted that $50 \%$ of programs provide routine in-house attending coverage (with $22 \%$ as needed for acuity or fellow inexperience) [9]. Neonatologists with home call may supervise advanced practice providers (APPs) at multiple clinical sites or cover lower acuity deliveries, as only $15 \%$ of general pediatricians/family physicians cover deliveries outside of rural settings [10].

To meet these coverage needs, providers may work long hours. American Board of Pediatrics (ABP) Maintenance of Certification data (2003-2015) show that $48 \%$ of neonatologists work $40-59 \mathrm{~h} /$ week, and concerningly, $47 \%$ work $>60 \mathrm{~h} /$ week [11]. On average, neonatologists work 22 weekend days, 45 nights on call, and 24 weeks on service annually [12]. Female pediatric subspecialists more frequently work part-time ( $17.5 \%$ vs $2.7 \%$ for males) [11]. Of the $6.8 \%$ "part-time" neonatologists, $36 \%$ work $\geq 40 \mathrm{~h} /$ week and $7 \%$ work $\geq 60 \mathrm{~h} /$ week [11]. Growing clinical demands offer job security, but require careful attention given potential impacts on work-life balance and recruitment.

Financial considerations can influence career planning [13]. Following the dissolution of fee-for-service compensation in 1983, $58 \%$ of surveyed neonatologists considered changing subspecialties due to "excessive clinical loads" and "inadequate compensation," although providers in academics and higher acuity NICUs reported higher job satisfaction [14]. In 2019, the median inclusive compensation for neonatologists was $\$ 256,000$ [12]. While neonatologists are currently among the highest-paid pediatric subspecialists, the 2021 Medicare Physician Fee Schedule may reduce future compensation [15]. Over the past decade, academic healthcare systems employed $\sim 50 \%$ of neonatologists [12],

\footnotetext{
${ }^{1}$ Department of Pediatrics, Division of Neonatology, University of Connecticut School of Medicine/Connecticut Children's, Hartford, CT, USA. ${ }^{2}$ Department of Pediatrics, Division of Neonatology, West Virginia University School of Medicine, Morgantown, WV, USA. ${ }^{3}$ Department of Pediatrics, Feinberg School of Medicine, Northwestern University, Chicago, IL, USA. ${ }^{4}$ Department of Pediatrics, Division of Neonatal-Perinatal Medicine, Yale University School of Medicine, New Haven, CT, USA. * A list of authors and their affiliations appears at the end of the paper. ${ }^{凶}$ email: jtrzask@connecticutchildrens.org
} 
compared to $38 \%$ in private practice [16]. Neonatologists are not equally distributed across states or population centers, with $\sim 84 \%$ practicing in metropolitan areas [12]. These factors impact compensation, with private practice neonatologists reporting $\$ 15,000$ greater annual compensation [12] and neonatologists in Northeast, Mid-Atlantic, and metropolitan areas earning less [17]. Female neonatologists also receive $3.7 \%$ less annual compensation, potentially resulting in a net loss of $\$ 430,000$ over a 35 -year career [11].

\section{CURRENT PHYSICIAN WORKFORCE}

Neonatology has had the most growth of any pediatric subspecialty over the past 20 years [18]. The number of NPM fellowship programs and first-year fellowship positions increased between 2016 and 2020, but fellowship applications decreased by $17 \%$ between 2015 and 2019 [19]. Although the number of practicing neonatologists has increased, the average age rose from 53.7 to 57 years between 2008 and 2015 [17], suggesting an aging workforce. Over the last 20 years, female American medical graduates drove the growth in the field [18]. Women now represent $75 \%$ of NPM fellows. International medical graduates represent $20 \%$ of the NPM workforce. Historically, the ABP has not collected racial and ethnic demographic data, but this information is necessary to assess trends in underrepresented in medicine (URiM) in NPM.

\section{PATHWAYS TO ACADEMIC PROMOTION}

NPM providers may participate in numerous types of scholarly activities, developing expertise in laboratory-based, translational or clinical research, quality improvement (QI), bioethics, education, global health, or epidemiology. However, academic faculty with non-traditional areas of scholarly pursuit may encounter illdefined promotional criteria and inconsistent definitions of tracks across institutions. Challenges securing sufficient funding, mentorship, and protected time to complete projects exist.

\section{Clinician}

Clinical faculty are instrumental to productive divisions and clinical programs. Although the responsibilities are intuitive, there is no uniform promotional pathway for "clinicians." Variability exists with respect to clinical time allocation, expectations for trainee education, institutional citizenship, and scholarly productivity.

NPM clinicians may develop expertise beyond direct patient care, such as through patient safety and QI initiatives. Numerous certificate programs are offered in this area, such as the Institute for Healthcare Improvement's online certification [20]. Other opportunities include biodesign and clinical informatics. In biodesign, clinicians work with interdisciplinary teams from nursing, engineering, design and computer science to develop new technologies to improve patient monitoring, evaluation, and diagnosis [21]. Clinical informatics is the scientific discipline focused on the effective use of biomedical information and knowledge in healthcare. There has been an exponential growth in the need for physicians trained in clinical informatics with the transition to electronic health records (EHR) [22]. Experts can transform healthcare by analyzing population data and designing or implementing communication systems to enhance individual and population health outcomes. The American Board of Medical Specialties approved clinical informatics as a board-eligible subspecialty in 2011. Beginning in 2023, board eligibility will require the completion of an ACGME-approved clinical informatics fellowship.

\section{Clinician-educator (CE)}

CE traditionally describes physicians with responsibility for trainee education [23-25]. CE tracks are typically non-tenured without

\begin{tabular}{|ll}
\hline Table 1. Key categories of educational scholarship. \\
\hline Category & Content supporting promotion \\
\hline Teaching & $\begin{array}{l}\text { Activity fostering learning } \\
\text { - Direct teaching } \\
\text { - Creating instructional materials }\end{array}$ \\
\hline Learner assessment & $\begin{array}{l}\text { Activities associated with measuring } \\
\text { learners' knowledge, skills, attitudes }\end{array}$ \\
\hline Curriculum development & $\begin{array}{l}\text { Development and design } \\
\text { - Longitudinal learner curriculum } \\
\text { - Educational activities including } \\
\text { evaluation }\end{array}$ \\
\hline Mentoring/advising & $\begin{array}{l}\text { Mentoring: } \\
\text { - Sustained, committed relationship } \\
\text { - Reciprocal benefits } \\
\text { Advising: }\end{array}$ \\
\hline - Limited relationship and time period \\
- Advisor serves as guide
\end{tabular}

research funding $[24,25]$. Attempts to define success in CE tracks have frequently relied on traditional promotional pathways, using productivity definitions created for physician-scientists (PS). As such, odds of holding a higher academic rank are lower for non-PS [26], and faculty devoting $>50 \%$ of the time to clinical care reported prolonged time to promotion [27]. Recently, the CE role was redefined with a focus on an educational scholarship [28], which dovetails nicely with the shift to competency-based education incorporating well-defined assessment and accreditation standards [29-31].

Developing career pathways with clear metrics can delineate the CE identity. In one survey, 55\% of respondents indicated master's level training was one way to gain relevant expertise [32], resulting in the development of graduate programs, including master of health professions education and master of medical education. In 2006, the Association of American Medical Colleges Group on Educational Affairs defined educational scholarship and identified specific activities that support academic promotion (Table 1) [33]. Having evidence of excellence in education by documenting quantity and quality of activities and evidence of engagement within the educational community by demonstrating contributions to its body of knowledge were identified as core principles of education scholarship [33].

\section{Physician-scientist}

Opportunities and challenges facing PS in contemporary academics are described previously in this series [34]. Limited institutional support, mentorship and funding created a "leaky pipeline," diminishing the number of neonatal PS. Interestingly, most pediatricians with R01-equivalent research awards are clustered at just 15 institutions [35]. Perceptions that PS receive lower compensation and have challenges with work-life balance may make research careers appear less attractive and feasible. Attrition of current PS and difficulty attracting new PS threatens to stall medical advancements.

Despite these challenges, it is critical to develop and promote opportunities to recruit and retain future PS. Laboratory-based neonatal physiology research has been rooted in large animal models with a focus on molecular biology and gene knockout models in rodents. Advances in technology have created expansive growth in stem cell and gene-editing research, as well as computational and systems biology research in genomics, 
Table 2. Opportunities and threats to the future of Neonatal-Perinatal Medicine.

Threats

Challenges meeting workforce demands

- Increased coverage needs from institutional "networks"

O Numerous units staffed by a provider group

O Range of acuity

O Increasing level I nursery coverage

inpatient specialty, coverage nights/weekends/holidays

- Increased census, in part due to increased survival of extremely

preterm/medically complex infants

- Paucity of data to determine representation of URiM in NPM

Competing subspecialties

- New pediatric hospital medicine subspecialty with 2-year fellowship program

Challenges facing academic advancement

- Increased focus on clinical productivity/RVUs, creating barriers to protected time

- Lack of clearly defined promotional pathways for clinicians and CE

- Attrition of the PS

O Difficulty securing grant funding, protected time, mentorship

O Perceived lifestyle challenges including financial compensation and work-life balance

Significant risk of burnout

- Increasing acuity of patient population

- Expectations of families/society

- Climate of litigation

- Increasing requirements of documentation, EHR

- Long hours, variability in schedule

- Significant physical demands of job, including night-call

- Numerous requirements for ongoing certification/credentialing
- Applicants to NPM fellowship may perceive challenges related to

\section{Opportunities}

Opportunities meeting workforce demands

- Flexibility/multiple models of practice

O Full-time and part-time positions

O Hybrid positions (varying acuity, teaching centers vs community NICU) O Collaboration with APPs

O Integration of technology (i.e., telemedicine) into care models

- Continued growth of the subspecialty

O Increase in number of fellowship programs and positions

- Increasing variety and acuity of pathology with advances in technology to keep the field fresh and exciting

- Prioritize recruitment and retention of URIM to reflect growing diversity of patient population and improve outcomes

Diversity in NPM career paths

- Choice of academic vs private practice

- Numerous scholarly pursuits available to complement clinical work

- Potential for customizable fellowship tracks

- Supplementation of training with non-clinical board-eligible subspecialties and fellowships

Growth of diverse academic niches

- Recognition of expertise in clinical, translational and basic science research, QI/PS, medical education, informatics, biodesign, ethics, global health, advocacy, public health/policy

- Ability to mentor trainees at different times and geographic locations, participate in communities of practice, and obtain additional training expanded by technology

- National/International Collaboratives

O Within NPM, or partnering with multidisciplinary organizations O Opportunities for research, optimization of patient care

O Development of communities of practice, professional network

Personal and professional satisfaction

- Adding many quality-adjusted life years with NICU interventions [51]

- Caring for infants and families

- Mentoring future generations of pediatricians/neonatologists

- Contributing to the body of research to optimize care provided

- Adaptation of clinical schedule for senior providers

- Leveraging growing technologies, such as telemedicine and EHR to positively impact both patient care and work-life balance

- Higher salary than other specialties in pediatrics

- Excellent job security

\section{Building and maintaining the workforce}

epigenomics, transcriptomics, proteomics, metabolomics and the study of complex gene networks underlying embryonic and fetal/ neonatal development and disease. Research in these areas offers great potential for the development of innovative diagnostic and therapeutic interventions.

\section{PATHWAYS TO PRIVATE PRACTICE PROMOTION}

Neonatologists in private practice have multiple avenues for career advancement, with opportunities for administrative roles in both practice and hospital management. Private practice physicians (PPPs) can own their practices, as a group or individually. National and state QI collaboration enables PPPs to impact local, regional, and national policy. Some PPPs conduct key implementation research by analyzing robust clinical databases [36, 37]. Even though almost $40 \%$ of neonatologists are PPPs, there is a paucity of literature about their contributions to NPM.

\section{FUTURE OF NPM PHYSICIANS/PROVIDERS}

The field of NPM has a bright future, filled with potential for career growth and professional satisfaction. Despite threats to the field, many opportunities and creative solutions are on the horizon. Table 2 presents a summary of key opportunities and perceived threats to the specialty.
The neonatology workforce faces increased clinical demands. Clinical networks can combine multiple nurseries under a single group, sometimes requiring providers to staff numerous hospitals across wide geographic areas. Varying team composition (with fewer APPs/trainees at community NICUs), long commutes, and substantial amounts of home call may negatively impact work-life integration in this model. As fewer general practitioners attend in the newborn nursery, coverage frequently falls to NPM networks. In addition, many NICUs reported sustained increases in census related to increasing survival of infants born extremely preterm or with significant congenital anomalies [38].

More providers are necessary, but meeting this demand presents a challenge. Many institutions increasingly rely on APPs to meet clinical needs. Despite the workforce expansion and clinical expertise offered by these providers, their incorporation into NICUs introduces challenges related to clarification of roles and responsibilities for direct clinical care, providing thorough training specific to neonatology, and ensuring opportunities for career advancement. In addition, ABP data affirms an aging workforce. Senior neonatologists may seek accommodations to decrease the physical demands of the job, such as limiting call/ clinical weeks, team acuity, or travel to remote clinical sites. If accommodations are not granted, these providers may seek nonclinical positions or retire early, shifting the clinical burden to 


\section{8}

younger faculty. Patients, families, trainees, and junior faculty will lose the benefit of these providers' years of valuable experience.

Similarly, continued investments are needed in neonatologists' professional development and workplace resources to avoid burnout. Ethical dilemmas and unmet expectations for survival or quality of life take an emotional toll. Factors that may promote resiliency include technological solutions or additional staff support to ease documentation requirements, along with the creation of leadership opportunities [39].

\section{Diverse opportunities for training and professional advancement}

The evolution of clinical practice models now permits novel, diverse avenues for professional advancement within NPM. Neonatologists can choose to excel in clinical care, providing holistic care for NICU families and leading interprofessional medical teams. Ensuring ongoing, evidence-based education for APPs, as well offering opportunities to participate in QI, teaching, and research, may help engage and retain these individuals in the NPM workforce. Some neonatologists find passion in education. Adept educators adjust their strategies to incorporate alternative methodologies, such as simulation and flipped classroom, to meet the needs of present-day trainees learning to think critically and navigate academic terrain. Educators must partner with PS colleagues to ensure physician trainees receive the optimal balance of clinical exposure and opportunities for scholarly investigation. Researchers may find their passion in identifying new treatments for medically complex patients, or ensuring that follow-up of NICU graduates informs future care. The creation of national and international collaboratives with access to large patient populations may rapidly advance knowledge and optimize practice.

Neonatologists can refocus their careers to mitigate changing personal needs, enhance work/life integration or pursue new interests. Division leaders may need to adapt existing positions to retain experienced providers and attract trainees, preserving and enhancing the workforce. Multi-site practice models create options for career advancement, including leadership roles at individual sites, as well as oversight for the larger practice's administrative, investigative, and QI efforts.

Expanding areas of scholarly activity for clinicians, CE, and PS often require specialized training and protected time. Customizable fellowship tracks may better support individual career development needs and enhance recruitment efforts. For example, a future clinician might only require 2 years of fellowship, similar to the pediatric hospital medicine fellowship [40]. Since medical advances have increased the survival of medically complex neonates, completing additional training in related subspecialty areas may improve patient care and garner recognition for these uniquely skilled clinicians. Examples include dual board certification or additional fellowship training, for example, in Neonatal Hemodynamics or Pediatric Cardiac Critical Care Medicine [41-45]. Trainees seeking exposure to scholarly activity could pursue the traditional 3-year NPM fellowship, with opportunities to pursue coursework, obtain an advanced degree, and complete scholarly projects. Individuals dedicated to pursuing clinical or laboratory-based investigation may obtain specialized research training at their institution (e.g., $\mathrm{PhD}$ ) or participate in national programs such as the Physician Scientist Development Program [46].

\section{Opportunities to optimize patient care}

Institutions can leverage expertise to impact care delivered across networks. Partnerships between tertiary care centers and community NICUs can remain robust through the development of practice guidelines, joint faculty development and QI efforts. These partnerships facilitate access to higher-level care, evidencebased updates across settings, and flexibility in the practice environment.

Black infants have inferior clinical outcomes and increased mortality in comparison to white infants $[47,48]$. A recent study demonstrated a significant benefit between patient outcomes and physician-racial concordance, and this benefit increased substantially with increasing patient comorbidities [49]. Increasing the diversity of the NPM workforce to accurately reflect the population and optimize patient care in underrepresented and underserved populations remains an area of critical importance.

While adopted more quickly in ambulatory specialties, telemedicine is gaining popularity in NPM. During the SARS-CoV-2 pandemic, telemedicine became more widespread, with allowances for billing with remote supervision. This enhanced providers' abilities to cover NICUs from home, and for tertiary centers to function as resources for community NICUs. Telemedicine presents an opportunity to expand expert neonatal care to rural/underserved areas and internationally. Potential uses of telemedicine include retinopathy of prematurity screening using remote digital retinal imaging, echocardiogram review and interpretation, subspecialty consultation, high-risk infant developmental follow-up, virtual family-centered rounds, and virtual education/simulation [50]. Future efforts should be directed towards optimizing and leveraging this technology to positively impact patient care as well as providers' work/life integration.

\section{CONCLUSION}

Despite evolving challenges, NPM remains an immensely rewarding career. Neonatologists work collaboratively, treat critically ill patients, educate future generations, and lead scholarly work. Job security is excellent and compensation is higher than in many other pediatric subspecialties. The ability to develop expertise within NPM provides personal and professional satisfaction. National and institutional leaders should build the workforce by retaining experienced providers, attracting future neonatologists, especially URiM and PS candidates, and engaging non-physician providers.

\section{REFERENCES}

1. Philip AG. The evolution of neonatology. Pediatr Res. 2005;58:799-815.

2. Alpert JS, Coles R. Careers in academic medicine. Triple threat or double fake. Arch Intern Med. 1988;148:1906-7.

3. Conti CR. Can the triple-threat academic physician exist in the new millennium? Clin Cardiol. 1999;22:499.

4. Stark AR. American Academy of Pediatrics Committee on Fetus and Newborn. Levels of neonatal care. Pediatrics. 2004;114:1341-7.

5. American Academy of Pediatrics Committee on Fetus and Newborn. Levels of neonatal care. Pediatrics. 2012;130:587-97.

6. Kourembanas S, Steinhorn R. In-house neonatology: what are we waiting for? Am J Respir Crit Care Med. 2010;182:728-9.

7. Horgan M. Neonatal outcome: role of change from on-call to in-house coverage model. Pediatr Res. 1997;41:153.

8. Bensouda B, Boucher J, Mandel R, Lachapelle J, Ali N. 24/7 in house attending staff coverage improves neonatal short-term outcomes: a retrospective study. Resuscitation. 2018;122:25-8.

9. Johnston L. Neonatology on-call models: a survey of members of the Organization of Neonatal Training Program Directors. unpublished data, 2019.

10. Wood AM, Jones MD Jr., Wood JH, Pan Z, Parker TA. Neonatal resuscitation skills among pediatricians and family physicians: is residency training preparing for postresidency practice? J Grad Med Educ. 2011;3:475-80.

11. Freed GL, Boyer DM, Van KD, Macy ML, McCormick J, Leslie LK. Variation in parttime work among pediatric subspecialties. J Pediatr. 2018;195:263-8.

12. Horowitz E, Feldman HA, Savich R. Neonatologist salary: factors, equity and gender. J Perinatol. 2019;39:359-65. 
13. Freed GL, Moran LM, Althouse LA, Van KD, Leslie LK, Research Advisory Committee of American Board of Pediatrics. Jobs and career plans of new pediatric subspecialists. Pediatrics. 2016;137:e20153298.

14. Clarke TA, Maniscalco WM, Taylor-Brown S, Roghmann KJ, Shapiro DL, HannonJohnson C. Job satisfaction and stress among neonatologists. Pediatrics. 1984;74:52-7.

15. Register F. Medicare Program. CY 2021 payment policies under the physician fee schedule and other changes to part B payment policies (CMS-1734-P). 2020. https://www.policymed.com/2020/09/cms-2021-proposed-physician-feeschedule-updates-to-telehealth-quality-payment-program-and-specialistreimbursement.html.

16. Freed GL, Dunham KM, Loveland-Cherry C, Martyn KK, Moote MJ. Private practice rates among pediatric subspecialists. Pediatrics. 2011;128:673-6.

17. American Board of Pediatrics. Pediatric physicians workforce data book, 20182019.

18. Macy ML, Leslie LK, Turner A, Freed GL. Growth and changes in the pediatric medical subspecialty workforce pipeline. Pediatr Res. 2020;89:1297-303.

19. National Resident Matching Program. Results and data: specialties matching service 2020 appointment year. Washington, DC: National Resident Matching Program; 2020

20. Institute for Healthcare Improvement. IHI Open School. 2021. http://www.ihi.org/ education/IHIOpenSchool/Courses/Pages/OpenSchoolCertificates.aspx.

21. Wall J, Wynne E, Krummel T. Biodesign process and culture to enable pediatric medical technology innovation. Semin Pediatr Surg. 2015;24:102-6.

22. American Medical Informatics Association. Clinical informatics fellows vital to future of value-based care. 2020. https://www.amia.org/news-and-publications/ press-release/clinical-informatics-fellows-vital-future-value-based-care.

23. Ahn J, Martin SK, Farnan JM, Fromme HB. The Graduate Medical Education Scholars Track: developing residents as clinician-educators during clinical training via a longitudinal, multimodal, and multidisciplinary track. Acad Med. 2018;93:214-9.

24. Fleming VM, Schindler N, Martin GJ, DaRosa DA. Separate and equitable promotion tracks for clinician-educators. JAMA. 2005;294:1101-4.

25. Greenberg L. The evolution of the clinician-educator in the United States and Canada: personal reflections over the last 45 years. Acad Med. 2018;93:1764-6.

26. Thomas PA, Diener-West M, Canto MI, Martin DR, Post WS, Streiff MB. Results of an academic promotion and career path survey of faculty at the Johns Hopkins University School of Medicine. Acad Med. 2004;79:258-64.

27. Buckley LM, Sanders K, Shih M, Hampton CL. Attitudes of clinical faculty about career progress, career success and recognition, and commitment to academic medicine. Results of a survey. Arch Intern Med. 2000;160:2625-9.

28. Varpio L, Gruppen L, Hu W, O'Brien B, Ten Cate O, Humphrey-Murto S, et al. Working definitions of the roles and an organizational structure in health professions education scholarship: initiating an international conversation. Acad Med. 2017;92:205-8.

29. Frank JR, Snell LS, Cate OT, Holmboe ES, Carraccio C, Swing SR, et al. Competencybased medical education: theory to practice. Med Teach. 2010;32:638-45.

30. Nasca TJ, Philibert I, Brigham T, Flynn TC. The next GME accreditation system-rationale and benefits. N Engl J Med. 2012;366:1051-6.

31. The Future of Medical Education in Canada - Post-graduate Project. The future of medical education in Canada: a collective vision for postgraduate medical education in Canada. 2012.

32. Sherbino J, Frank JR, Snell L. Defining the key roles and competencies of the clinician-educator of the 21st century: a national mixed-methods study. Acad Med. 2014;89:783-9.

33. Simpson D, Brownell Anderson M. Educational scholarship: how do we define and acknowledge it? 2006. www.aamc.org/professional-development/affinitygroups/gfa/faculty-vitae/defining-educational-scholarship.

34. Bauserman $M$, Vasquez $M$, Chess PR, Carbajal $M$, ONTPD Fellowship Directors Writing Group, Good M.J Perinatol. 2021. https://doi.org/10.1038/s41372-02100957-3. Online ahead of print.

35. Good M, McElroy SJ, Berger JN, Wynn JL. Name and characteristics of National Institutes of Health R01-funded pediatric physician-scientists: hope and challenges for the vanishing pediatric physician-scientists. JAMA Pediatr. 2018;172:297-9.

36. Escobar GJ, Fischer A, Kremers R, Usatin MS, Macedo AM, Gardner MN. Rapid retrieval of neonatal outcomes data: the Kaiser Permanente Neonatal Minimum Data Set. Qual Manag Health Care. 1997;5:19-33.
37. Spitzer AR, Ellsbury D, Clark RH. The Pediatrix BabySteps(R) Data Warehouse-a unique national resource for improving outcomes for neonates. Indian J Pediatr. 2015;82:71-9.

38. Capan M, Hoover S, Jackson EV, Paul D, Locke R. Time series analysis for forecasting hospital census: application to the neonatal intensive care unit. Appl Clin Inf. 2016;7:275-89.

39. DeChant PF, Acs A, Rhee KB, Boulanger TS, Snowdon JL, Tutty MA, et al. Effect of organization-directed workplace interventions on physician burnout: a systematic review. Mayo Clin Proc Innov Qual Outcomes. 2019;3:384-408.

40. Accreditation Council for Graduate Medical Education. ACGME program requirements for graduate medical education in pediatric hospital medicine. 2020. www acgme.org/Portals/0/PFAssets/ProgramRequirements/334_PediatricHospitalMedicine 2020.pdf?ver=2020-06-29-163350-912020.

41. Toronto Centre for Neonatal Health. Advanced neonatal training: neonatal hemodynamics subspecialty fellowship. Toronto Centre for Neonatal Health. 2021. https:// torontocentreforneonatalhealth.com/education-opportunities/fellowships.

42. University of lowa Healthcare. Neonatology Hemodynamics Fellowship. 2022 https://gme.medicine.uiowa.edu/neonatology-hemodynamics-fellowship2021.

43. Boston Children's Hospital. Heart Center Cardiovascular Intensive Care Clinical Fellowship. 2022. https://www.childrenshospital.org/centers-and-services/centers/heartcenter/education-and-training/cardiology-fellowship-program/cardiovascularintensive-care-clinical-fellowship2021.

44. Children's Hospital of Philadelphia. Pediatric Cardiac Critical Care Medicine Fellowship. Children's Hospital of Philadelphia. 2021 https://www.chop.edu/ pediatric-fellowships/pediatric-cardiac-critical-care-medicine-fellowship.

45. McGill University. Neonatal Hemodynamics Clinical Research Fellowship Program 2022. https://www.mcgill.ca/peds/education-training/pgme/programs/neonatology/ fellowship2021.

46. Association of Medical School Pediatric Department Chairs. Physician Scientist Development Program. Association of Medical School Pediatric Department Chairs. 2021. https://amspdc-psdp.org/.

47. Collins JW Jr., David RJ. Racial disparity in low birth weight and infant mortality. Clin Perinatol. 2009;36:63-73.

48. Lu MC, Halfon N. Racial and ethnic disparities in birth outcomes: a life-course perspective. Matern Child Health J. 2003;7:13-30.

49. Greenwood BN, Hardeman RR, Huang L, Sojourner A. Physician-patient racial concordance and disparities in birthing mortality for newborns. Proc Natl Acad Sci USA. 2020;117:21194-200.

50. Hoffman AM, Lapcharoensap W, Huynh T, Lund K. Historical perspectives: telemedicine in neonatology. Neoreviews. 2019;20:e113-e23.

51. Lantos JD, Meadow WL. Costs and end-of-life care in the NICU: lessons for the MICU? J Law Med Ethics. 2011;39:194-200.

\section{AUTHOR CONTRIBUTIONS}

JMT, ASK, PM, and LCJ conceptualized, drafted, reviewed, revised, and approved the manuscript as submitted, and agreed to be accountable for all aspects of the work. $\mathrm{BS}, \mathrm{JE}, \mathrm{MG}, \mathrm{DO}, \mathrm{MCS}, \mathrm{KS}$, and AP critically reviewed the manuscript. Consortium authors conceptualized the manuscript.

\section{COMPETING INTERESTS}

The authors declare no competing interests.

\section{ADDITIONAL INFORMATION}

Correspondence and requests for materials should be addressed to Jennifer $M$. Trzaski.

Reprints and permission information is available at http://www.nature.com/ reprints

Publisher's note Springer Nature remains neutral with regard to jurisdictional claims in published maps and institutional affiliations. 


\section{ONTPD FELLOWSHIP DIRECTORS WRITING GROUP}

Melissa Bauserman ${ }^{5}$, Heather French ${ }^{6}$, Kris Reber $^{7}$, Erin Cicalese ${ }^{8}$, Karena Lawrence ${ }^{9}$, Brittany Schwarz ${ }^{10}$, Allison Payne $^{11}$, Robert Angert ${ }^{8}$, Maria Gillam-Krakauer ${ }^{12}$, Jotishna Sharma ${ }^{13}$, Elizabeth Bonachea ${ }^{14}$, Margarita Vasquez ${ }^{15}$, Patricia Chess ${ }^{16}$, Rita Dadiz ${ }^{17}$, Josephine Enciso ${ }^{18}$, Alison Falck ${ }^{19}$, Mackenzie Frost ${ }^{6}$, Megan Gray ${ }^{20}$, Susan Izatt ${ }^{21}$, Sara Kane ${ }^{22}$, Melissa Carbajal ${ }^{23}$, Kristen Leeman ${ }^{24}$, Sabrina Malik ${ }^{25}$, Misty Good ${ }^{26}$, Jayasree Nair ${ }^{27}$, Deirdre O'Reilly ${ }^{28}$, Taylor Sawyer ${ }^{20}$, M. Cody Smith ${ }^{29}$, Kate Stanley ${ }^{30}$ and Jennifer Wambach ${ }^{5}$

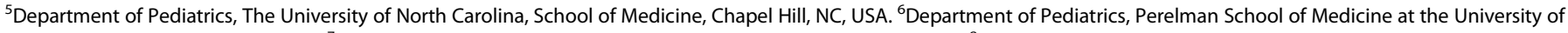

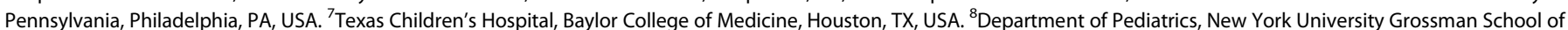

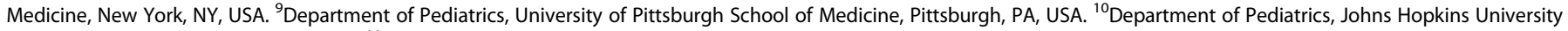

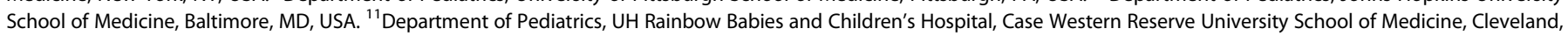

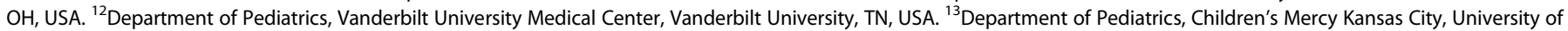

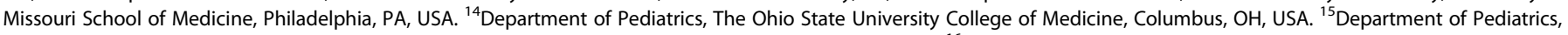

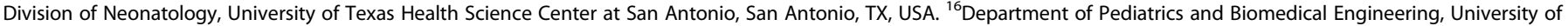

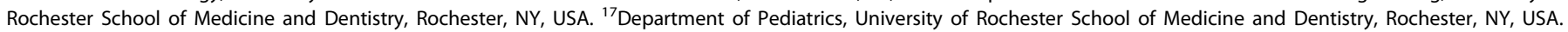

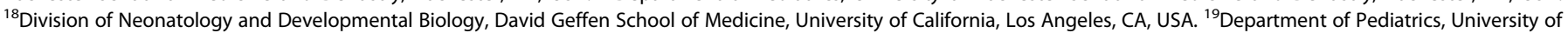

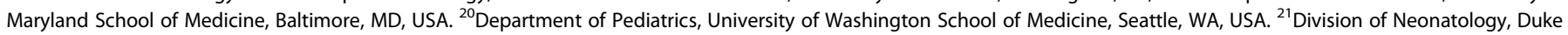

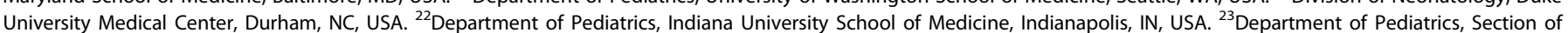

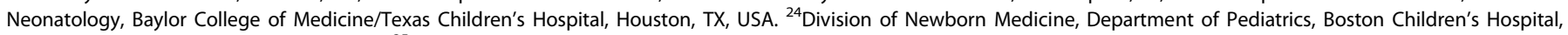

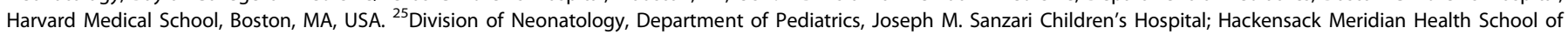

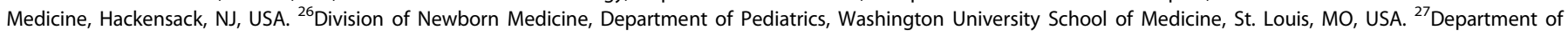

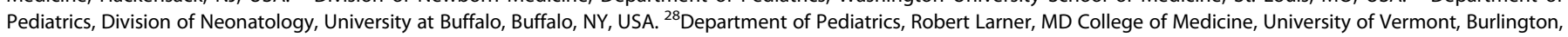

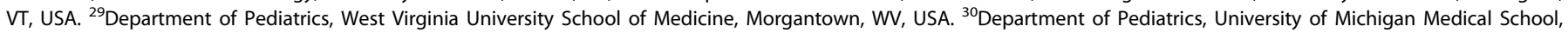
Michigan Medicine, Ann Arbor, MI, USA.
} 